\title{
Bronchial Arteries Embolization in Tuberculosis- Related Recurrent Hemoptysis with Complete Right Lung Atelectasis: A Case Report
}

\author{
Yulia Devina Suci Kusumastrini ${ }^{1}$, Ariani Permatasari ${ }^{1,2 *}$ (D) \\ ${ }^{1}$ Department of Pulmonology and Respiratory Medicine, Faculty of Medicine, Universitas Airlangga, Surabaya, Indonesia. \\ ${ }^{2}$ Department of Pulmonology and Respiratory Medicine, Dr. Soetomo General Hospital, Surabaya, Indonesia.
}

\begin{tabular}{l} 
ARTICLE INFO \\
\hline Article history: \\
Received 25 October 2021 \\
Received in revised form 17 \\
January 2022 \\
Accepted 22 January 2022 \\
Available online 30 January 2022 \\
\hline Keywords: \\
Bronchial artery embolization, \\
Recurrent hemoptysis, \\
Tuberculosis. \\
\hline
\end{tabular}

\begin{abstract}
Introduction: Hemoptysis is an emergency condition with high morbidity and mortality which requires immediate treatment. Active tuberculosis (TB) and posttubercular sequelae can result in hemoptysis with the most common source is from bronchial artery.

Case: We reported a 22-year-old man who presented with shortness of breath and recurrent hemoptysis. A chest X-Ray showed total atelectasis right lung due to obstructive airway. After aspiration clotting blood in bronchus and instillation adrenalin with fiber optic bronchoscopy, the atelectasis totally disappeared. Computed tomography angiography (CTA) showed prominent vascular lesions from the apical right pulmonary artery, right brachialis artery, and branch of the posterior intercostal artery. The patient was referred to the interventional unit of the radiology department in Dr. Soetomo General Hospital and underwent bronchial artery embolization. After this procedure, his symptoms resolved completely and he was discharged after a week with $2^{\text {nd }}$ category anti-tuberculosis drugs (ATD). 6 months of follow-up, he no longer experienced hemoptysis.

Conclusion: Recurrent hemoptysis needs optimal management, including diagnostic with chest radiography, CT and bronchoscopy. Treatment with bronchoscopy and bronchial artery embolization will reduce mortality and morbidity in patients with hemoptysis.
\end{abstract}

\section{INTRODUCTION}

Hemoptysis is a complication of pulmonary tuberculosis (TB) which causes a high mortality rate if not treated properly. It can cause total airway obstruction and obstructive atelectasis. Atelectasis which develops rapidly over a large area can lead to hypoxia and respiratory failure. ${ }^{1}$

The mortality rate from hemoptysis which is not treated appropriately is up to $50-60 \%$. In hemoptysis, the most common cause of death is asphyxia rather than bleeding. ${ }^{2}$ Hemoptysis can occur in patients with relapse pulmonary TB due to pulmonary parenchymal disorders and vascular complications from previous TB infection. ${ }^{3}$

Management for massive or recurrent hemoptysis is divided into invasive and non-invasive procedure. Pulmonary resection has been performed in massive hemoptysis, but the mortality rate from this procedure is more than $40 \%{ }^{1}$ Non-invasive procedures are required for the management of hemoptysis. One of the noninvasive procedures is bronchial artery embolization which was first performed by Remy, et al. in 1973 on massive hemoptysis. ${ }^{2}$

In the last 3 decades, it has been recognized that embolization is the safest and most effective non-surgical procedure for primary treatment of massive or recurrent hemoptysis. Embolization is the treatment option for life-

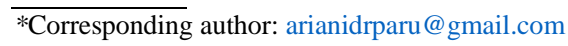

Jurnal Respirasi (Journal of Respirology), p-ISSN: 2407-0831; e-ISSN: 2621-8372.

Accredited No. 200/M/KPT/2020; Available at https://e-journal.unair.ac.id/JR. DOI: 10.20473/jr.v8-I.1.2022.33-38

(c) (P) This work is licensed under a Creative Commons Attribution-Share Alike 4.0 International License. 
threatening hemoptysis. Patients with massive hemoptysis should always be considered a lifethreatening condition which requires prompt, appropriate, and effective therapy. We reported a patient with total atelectasis due to recurrent hemoptysis and was treated with bronchial artery embolization. ${ }^{4}$

\section{CASE}

A 22-year-old man was presented to the hospital with hemoptysis. The patient complained of hemoptysis for 2 weeks before admission, bright red, with volume $\pm 50 \mathrm{cc}$. The amount increased the day before admission. Shortness of breath for 7 days before admission, cough with mucous sputum for 1 month. Loss of body weight 3 $\mathrm{kg}$ for 2 months, loss of appetite, and night sweating.

Before being admitted to Dr. Soetomo General Hospital, the patient was admitted to Lamongan Hospital on 2 November 2019 with hemoptysis. After 12 days of treatment in Lamongan Hospital, the patient was still complaining of hemoptysis, hence the patient was referred to Dr. Soetomo General Hospital.

His past medical history revealed he had hemoptysis in 2018 about \pm 5 cc for two weeks. The patient got positive results from Acid Fast Bacilli (AFB) test, then received standard treatment of $1^{\text {st }}$ category antituberculosis drugs (ATD). After receiving TB treatment, his hemoptysis was getting better, even though sometimes there was still a blood streak after a hard cough. He is a university student, never smokes or drinks alcohol. He refused a history of asthma, hypertension, diabetes, allergy, confusion, autoimmunity, and other diseases. None of his family or close friends have the same symptom or history of TB.

Physical examination showed tachypnea $28 \mathrm{x} / \mathrm{min}$ and saturation $92 \%$ with nasal $\mathrm{O}_{2} 3 \mathrm{lpm}$. Head and neck examination found conjunctiva anemic and trachea deviation to the right. Chest examination found decreased chest expansion on the right side and vocal fremitus decreased in right chest. Chest auscultation found vesicular sound decreased in the right lung, no rhonchi or wheezing. Laboratory findings showed leukocytosis (white blood cell count of 11,740 cell $/ \mathrm{mm}^{3}$ ) and granulocytosis (neutrophil count $81.3 \%$ ). Blood gas analysis was normal acid base with mild hypoxemia. Chest radiograph revealed homogenous opacity in the right hemithorax with trachea deviation to the right side (Figure 1b), compared to the previous chest radiograph which revealed homogenous opacity only in the apex right hemithorax (Figure 1a).

The patient underwent Fiber Optic Bronchoscopy (FOB). From FOB, we found active bleeding in the trachea wall and segment B2 superior lobe right lung. Then we aspirated clotting blood in the bronchus and instillation adrenalin with normal saline cold (Figure 2a, 2b). After FOB, chest radiograph showed the atelectasis totally disappeared (Figure 2c).

A day after FOB, the patient was still complaining of bloody cough about $\pm 5 \mathrm{cc}$. The patient underwent Multi Slice Computed Tomography Angiography (MSCTA) thorax with contrast. The results from MSCTA (Figure 3) found fibro-infiltrate with multiple cavities with the most significant size $+/-3.5 \times 3.1 \times 5.3 \mathrm{~cm}$. We found lesions with prominent vascular feeding from artery segment apical right artery pulmonalis, right brachialis artery, and branch artery posterior intercostal as height right thoracal vertebra 5-6. There was dilatation of branches artery in this region.

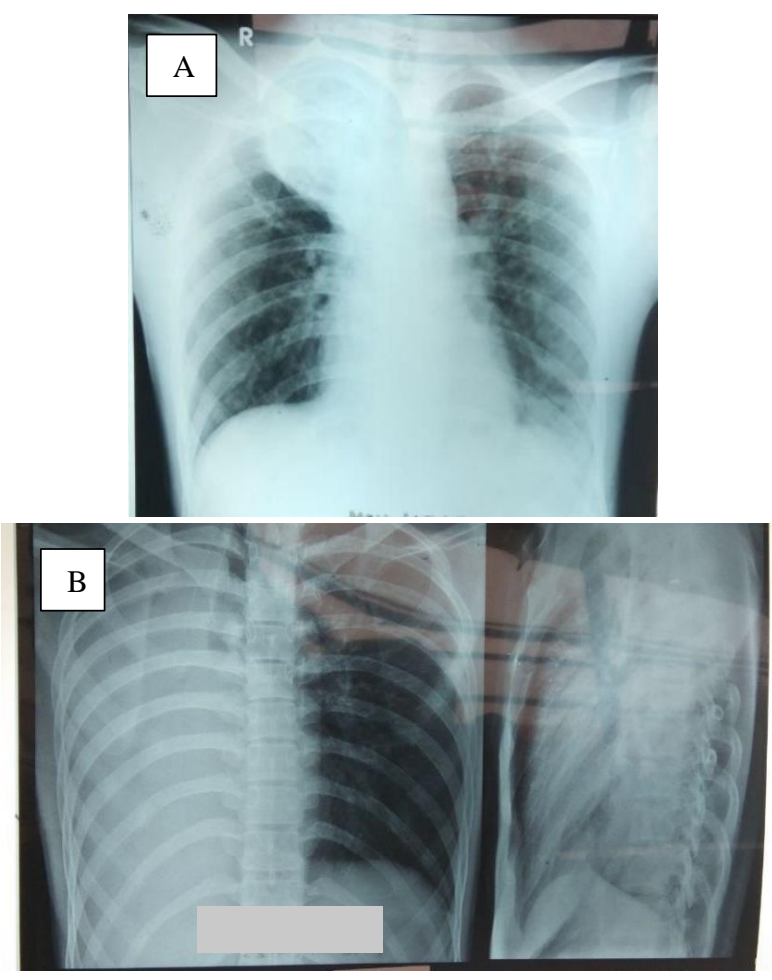

Figure 1. A) Chet X-ray taken on 2 November 2019, there was a homogeneous opacity at the apex of the right hemithorax; B) Chest X-Ray taken on 14 November 2019, there was a homogeneous right hemithorax with a deviation of the trachea to the right side. 


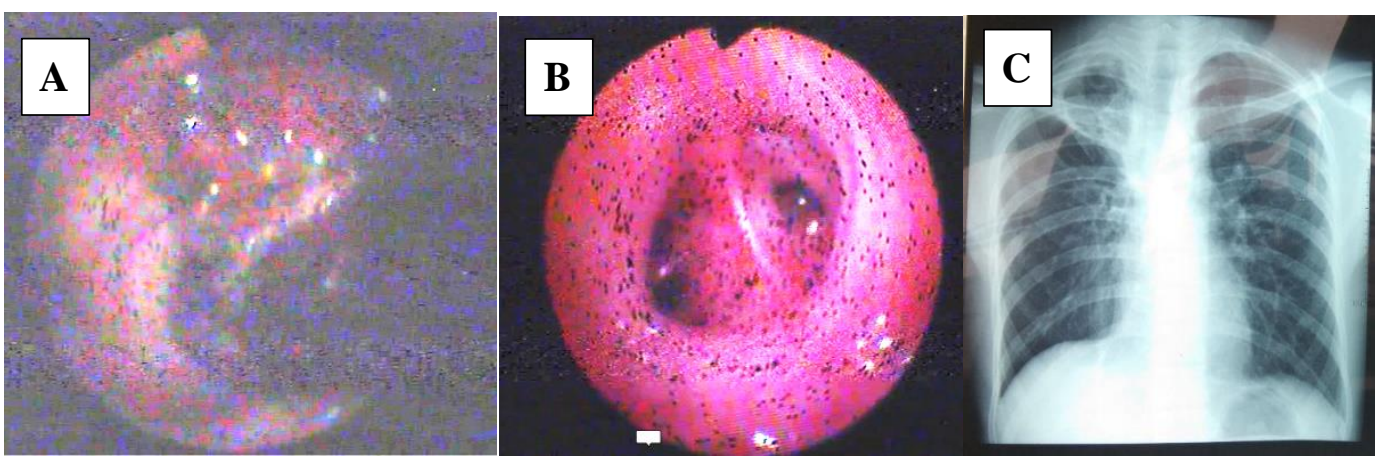

Figure 2. A) Bronchoscopy before aspiration of clotting blood; B) After aspiration clotting blood; C) Chest X-Ray taken on 22 November 2019 after FOB showed the atelectasis disappeared.

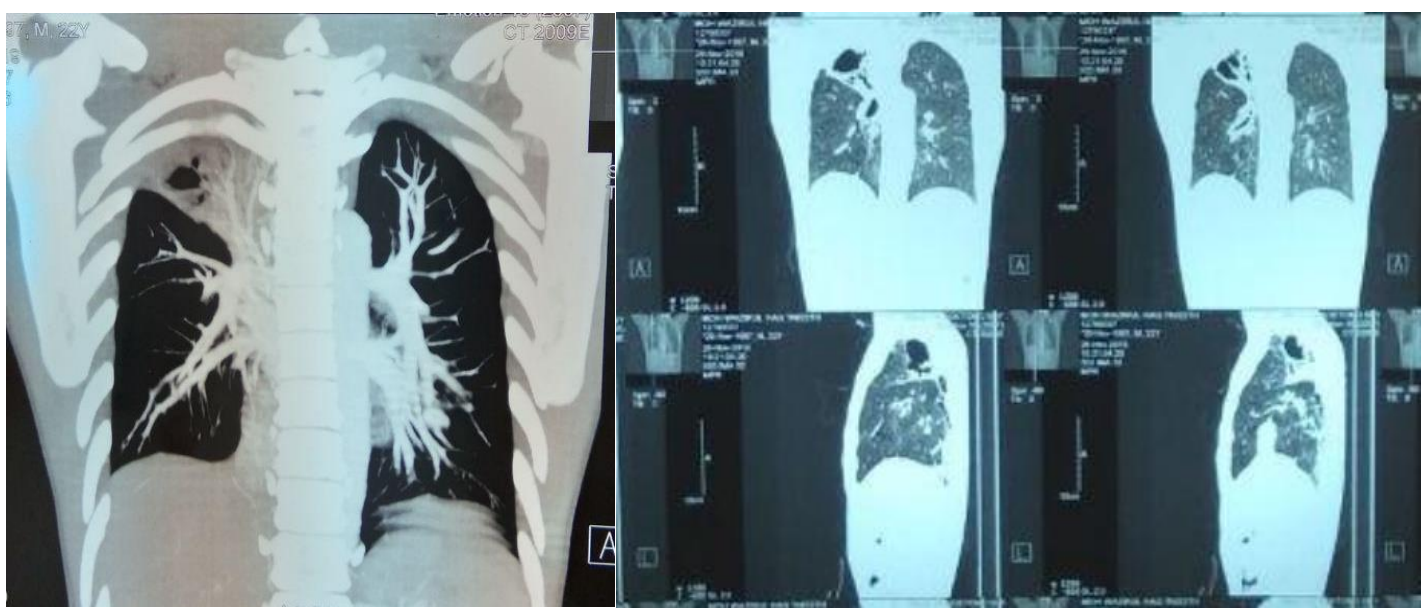

Figure 3. Thoracic MSCTA taken on 26 November 2019

Based on thoracic MSCTA on 26 November 2019 (Figure 3), the patient was then consulted to interventional radiology division for right bronchial artery embolization. We performed local anesthesia with lidocaine 2 ampules in the right inguinal, then incision until the femoral artery was visible. We inserted catheter to femoralis artery, a direct catheter to iliac extrenum artery, right common iliac artery, aorta abdominals, aorta thoracic, and finally entered right bronchial artery. The patient was embolized with Polyvinyl Alcohol Particles (PVA) for 350 - 500 cc (Figure 4).

\section{Outcome}

After the embolization of right bronchial artery, the patient never complained about hemoptysis and shortness of breath. 2 days after embolization, we performed chest X-Ray evaluation (Figure 5). The patient was then discharged with $2^{\text {nd }}$ ATD consisted of isoniazid $300 \mathrm{mg}$, rifampicin $450 \mathrm{mg}$, pyrazinamide 1250 $\mathrm{mg}$, ethambutol $750 \mathrm{mg}$, and streptomycin injection 750 $\mathrm{mg}$ intramuscular.

\section{DISCUSSION}

Hemoptysis is classified into massive and nonmassive based on the rate of bleeding. Non-massive if hemoptysis volume $<100 \mathrm{ml} / 24$ hours, while massive is

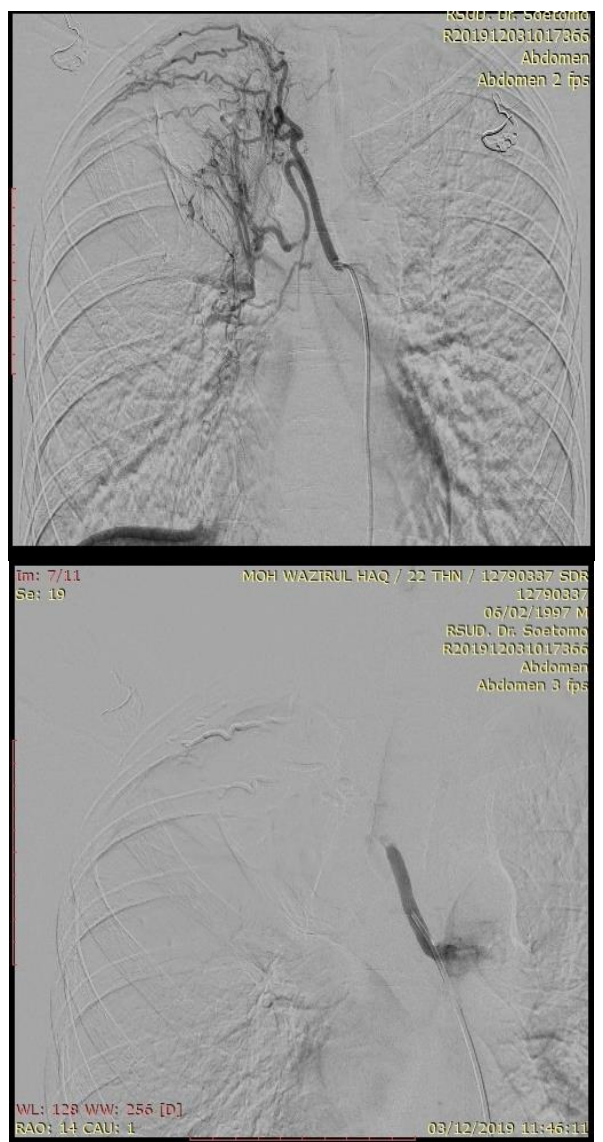

Figure 4. Before and after embolization of bronchial artery 


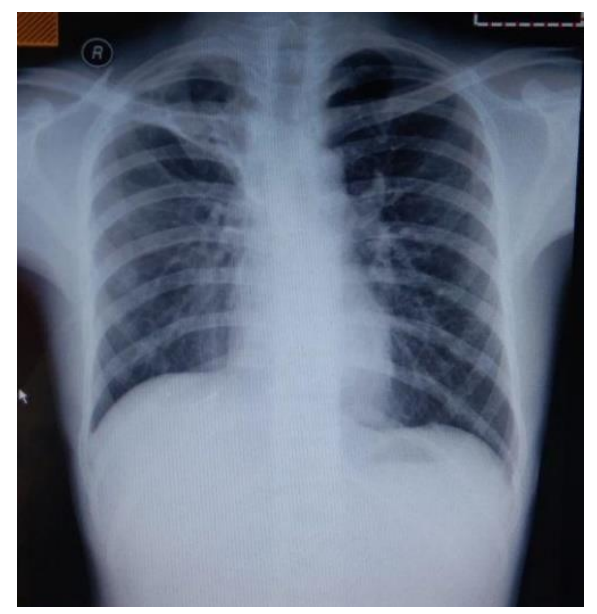

Figure 5. Chest X-ray a day after embolization taken on 4 December 2019

between $200-1,000 \mathrm{ml} / 24$ hours. The volume of fluid that can be accommodated in the respiratory tract is 100 $200 \mathrm{ml}$. Therefore, hemoptysis can be categorized as non-massive if the bleeding is less than $200 \mathrm{ml}^{5,6}$ Recurrent hemoptysis is defined as hemoptysis that occurs when the patient experiences bloody cough after experiencing a previous episode of hemoptysis, after receiving medical therapy or after interventional therapy, and requires re-hospitalization. ${ }^{7}$

In this case, the patient complained of coughing up blood with a total volume of 50-250 cc per day occurring for more than 2 weeks. Complaints of coughing up blood with the same volume also occurred in the previous year, thus the patient was included in the category of recurrent hemoptysis.

The lungs have a dual blood supply through the pulmonary arteries, whereas the pulmonary artery circulation provides gas exchange with the alveoli and provides $99 \%$ of the arterial supply. ${ }^{8}$ As internal blood vessels, bronchial arteries provide $1 \%$ of the total blood supply from the cardiac output and serve as nutrients to the lungs. Physiologically, there is a relationship between the two circulatory systems at different anatomical locations (bronchopulmonary, pre-capillary, capillary, and post-capillary). ${ }^{9}$

In relapsed $\mathrm{TB}$, hemoptysis results from damage and structural remodeling of the lung parenchyma and its vasculature. Recurrent or chronic infection and inflammation can cause permanent damage and dilatation of blood vessels in bronchial artery. Presence of infection and/or inflammation in normal vascular anastomoses between bronchial and pulmonary blood vessels become larger, thus there is a lot of blood flow through the dilated bronchial arteries. The bronchial vessels become hypertrophied and ectatic. In addition, new and collateral blood vessels, aided by the release of angiogenic growth factors such as vascular endothelial growth factor, have thin walls and are prone to rupture. Hypervascularity, structural disturbances, and exposure to infection in the blood vessels make bleeding easier. ${ }^{7,10}$ In this case, from MSCTA we found prominent vascular feeding from artery segment apical right artery pulmonalis, right brachialis artery, and branch artery posterior intercostal at the level of VT5 - VT6 which could cause the bleeding.

The main goal of diagnostics in hemoptysis is to identify the location and cause of bleeding. Computed tomography (CT) and bronchoscopy are accurate techniques for diagnosing and identifying the location of the source of bleeding. ${ }^{11}$ Modoni, et al. showed that bronchoscopy could detect the source of bleeding (anatomical location, lobes, and lungs) better when performed within 48 hours of the occurrence hemoptysis episodes. Bronchoscopy is very useful in patients with massive or moderate bleeding. ${ }^{12}$

Computed tomography angiography (CTA) is recognized as a comprehensive, non-invasive method used to evaluate patients with hemoptysis, including detecting the primary cause of hemoptysis, locating active bleeding, and planning surgery or embolization. ${ }^{13}$ It is more advanced to arteriography in detection of bleeding from bronchial, non-bronchial systemic arteries, and from inflammatory pulmonary artery aneurysms. ${ }^{14}$ It can identify the exact location of the bronchial arteries and the presence of variations in the bronchial arteries. ${ }^{15}$

Bronchoscopy can be used to determine the source of bleeding from the airway. It is considered for the following conditions: (1) Massive hemoptysis, (2) Non-invasive hemoptysis with radiological abnormalities, (3) Non-massive hemoptysis with risk factors for lung cancer with normal radiology, and (4) Cases of non-invasive hemoptysis with normal radiology and no risk factors of lung cancer. ${ }^{16}$

Bronchoscopy plays an essential role in the diagnosis and management of hemoptysis. The sensitivity of bronchoscopy in determining the location of bleeding is $73-93 \%$ and identifying the cause of hemoptysis in $2.5-8 \%$ of cases. Bronchoscopy can be helpful for diagnostic tissue collection (microbiological samples, cytology, or histological examination). ${ }^{17}$ In this case, the diagnosis of hemoptysis was made with chest X-ray, CT chest angiography with contrast, and FOB. From FOB, we found that there was active bleeding in the tracheal wall and segment B2 of the right superior lobe of the lung.

After finding the source of bleeding, there are several therapies which can be used to treating hemoptysis. Tranexamic acid is known as drug which can control bleeding. It is a lysine derivative which can inhibit fibrinolysis by blocking lysine-binding sites on 
plasminogen. It can decrease the duration and volume of hemoptysis. ${ }^{18}$ Rigid bronchoscopy can provide the advantage of a safe and patent airway to suppress the location of bronchial bleeding and maintain oxygenation and ventilation of the lungs without bleeding. It causes widening of the lumen, hence rigid suction can be performed, which can clear blood clots which cause obstruction. ${ }^{19}$

There is also endobronchial therapy which can be given during broncoscopy. Several agents are used for endobronchial instillation in order to maintain hemostasis, especially when the source of bleeding is beyond the reach of the bronchoscope. Irrigation with normal saline at $40^{\circ} \mathrm{C}$ in $50 \mathrm{cc}$ aliquots is performed with rigid bronchoscopy. Each patient receives 300-750 cc of cold saline lavage at the bleeding area. Epinephrine and norepinephrine are used in cases of massive hemoptysis. The low concentration of epinephrine used is $1: 100,000$ with a maximum dose of $0.6 \mathrm{mg}$. Electrocardiographic monitoring is required when taking epinephrine. Avoid using epinephrine in patients with coronary artery disease and arrhythmias. There are several other ways to treat bleeding as much as possible, including balloon compression via an endobronchial procedure. ${ }^{20}$

Another therapy is Bronchial Artery Embolization (BAE), defined as the initial treatment option for massive or recurrent hemoptysis, where the mortality rate ranges from $7.1 \%$ to $18.2 \%$. BAE is more effective and reduces mortality and morbidity rates than alternative surgical procedures. ${ }^{5}$ The most feared complication of BAE is embolization of the anterior spinal artery, which results in spinal cord ischemia. Over the last few years, this complication has been rare $(0$ $1 \%)^{18}$

The last option therapy is surgery. Surgery is the definitive treatment in patients with massive hemoptysis, the source of bleeding has been identified, pulmonary function is adequate, there are no contraindications to surgery, have contraindications to bronchial artery embolization or suspicion of pulmonary artery perforation, and mycetoma rupture with multiple contralateral arteries. An outside report in some countries, partial resection surgery with VATS was performed. ${ }^{21}$ Brick, et al. reported that lobectomy was the most frequently used method $(51.1 \%)$ for the management of hemoptysis caused by pulmonary tuberculosis. $^{22}$

In this case, tranexamic acid therapy was given as anti-bleeding, FOB with cold saline lavage and epinephrine, and bronchial artery embolization, which is the main cause of coughing up blood experienced by the patient. To this day, the patient no longer complained of coughing up blood.

\section{CONCLUSION}

Diagnostic for recurrent hemoptysis focused on the localization of the bleeding site and underlying cause. It can be performed by chest radiography, CT, and bronchoscopy. Immediate treatment with bronchoscopy and embolization are the safest and most effective nonsurgical procedure for primary treatment of massive or recurrent hemoptysis. Treatment with bronchoscopy and bronchial artery embolization can reduce mortality and morbidity in patients with hemoptysis.

\section{Acknowledgments}

We would like to thank Departement of Pulmonology and Respiratory Medicine, Dr. Soetomo General Hospital for supporting this case report.

\section{Confict of Interest}

The author stated there is no conflict of interest in this study.

\section{Funding}

This study does not receive any funding.

\section{Authors' Contributions}

Conceiving the study, writing manuscript: YDCK and AP. Collecting data of patient: YDSK. Reviewing and revising: AP. All authors contributed and have approved the final version.

\section{REFERENCES}

1. Ray K, Bodenham A, Paramasivam E. Pulmonary Atelectasis in Anaesthesia and Critical Care. Contin Educ Anaesthesia, Crit Care Pain 2014; 14: 236245. [GoogleScholar]

2. Vadala R, Desai M, Arora A, et al. Effective Control of Massive Haemoptysis in Pulmonary Tuberculosis Patients by Bronchial Artery Embolisation - A Report of 3 Cases. 2017; 4: 726728. [GoogleScholar]

3. Ashish Bhalla, Ashok Kumar Pannu VS. Etiology and Outcome of Moderate-to-massive Hemoptysis: Experience from a Tertiary Care Center of North India. Int J Mycobacteriology 2017; 6: 239-245. [CrossRef] [PubMed]

4. Bronchialarterienembolisation I. Radiologic Management of Haemoptysis: Diagnostic and Interventional Bronchial Arterial Embolisation Radiologisches Management von Hämoptysen : 2015; 248-259. [PubMed]

5. Yulisar RN, Kamelia T. Diagnosis dan Tata Laksana Terkini Hemoptisis. Indones J CHEST Crit Emerg Med 2016; 3: 57-66. [GoogleScholar] 
6. Atikawati D, Marhana IA. Sequelae Tuberkulosis dengan Hemoptisis Rekurens. J Respirasi 2019; 1: 88. [CrossRef]

7. Kathuria H, Hollingsworth HM, Vilvendhan R, et al. Management of Life-Threatening Hemoptysis. 2020; 1-9. [CrossRef] [PubMed]

8. Sakina S, Syafa'ah I. The Role of Bronchoscopy in Hemoptysis. J Respirasi 2020; 6: 55. [CrossRef]

9. Heunks L, Demoule A, Windisch W. ERS Monograph Pulmonary Emergencies, (2016).

10. Seedat UF, Seedat F. Post-Primary Pulmonary TB Haemoptysis - When There is More than Meets the Eye. Respir Med Case Reports 2018; 25: 96-99. [CrossRef] [PubMed]

11. Mondoni M, Carlucci P, Job S, et al. Observational, Multicentre Study on the Epidemiology of Haemoptysis. Eur Respir J 2018; 51: 10-13. [CrossRef] [PubMed]

12. Mondoni $\mathrm{M}$, Carlucci $\mathrm{P}$, Cipolla $\mathrm{G}$, et al. Bronchoscopy to Assess Patients with Hemoptysis: Which is the Optimal Timing? BMC Pulm Med 2019; 19: 1-6. [PubMed]

13. Seon HJ, Kim YH, Kwon YS. Localization of Bleeding Sites in Patients with Hemoptysis Based on Their Chest Computed Tomography Findings: A Retrospective Cohort Study. BMC Pulm Med 2016; 16: 1-6. [CrossRef] [PubMed]

14. Piracha S, Mahmood A, Qayyum N, et al. Massive Haemoptysis Secondary to Mycotic Pulmonary Artery Aneurysm in Subacute Invasive Aspergillosis. BMJ Case Rep 2018; 2018: 1-4. [CrossRef] [PubMed]
15. Noë GD, Jaffé SM, Molan MP. CT and CT Angiography in Massive Haemoptysis with Emphasis on Pre-Embolization Assessment. Clin Radiol 2011; 66: 869-875. [CrossRef] [PubMed]

16. Cardenas-Garcia J, Feller-Kopman D. POINT: Should All Initial Episodes of Hemoptysis Be Evaluated by Bronchoscopy? Yes. Chest 2018; 153: 302-305. [CrossRef] [PubMed]

17. Ittrich $\mathrm{H}$, Bockhorn $\mathrm{M}$, Klose $\mathrm{H}$, et al. The Diagnosis and Treatment of Hemoptysis. Dtsch Arztebl Int 2017; 114: 371-381. [PubMed]

18. Gagnon S, Quigley N, Dutau H, et al. Approach to Hemoptysis in the Modern Era. Can Respir J; 2017. Epub ahead of print 2017. DOI: 10.1155/2017/1565030. [CrossRef] [PubMed]

19. Radchenko C, Alraiyes AH, Shojaee S. A Systematic Approach to the Management of Massive Hemoptysis. 9. Epub ahead of print 2017. DOI: 10.21037/jtd.2017.06.41. [CrossRef] [PubMed]

20. Jin $\mathrm{F}, \mathrm{Li} \mathrm{Q}$, Bai $\mathrm{C}$, et al. Chinese Expert Recommendation for Diagnosis and Treatment of Massive Hemoptysis. Respiration 2020; 99: 83-92. [CrossRef] [PubMed]

21. Dokhan AL, Abd Elaziz ME, Yousif M. Surgical Management of Hemoptysis in Pulmonary Tuberculous Patients. J Egypt Soc Cardio-Thoracic Surg 2016; 24: 78-85. [CrossRef]

22. Yun JS, Song SY, Na KJ, et al. Surgery for Hemoptysis in Patients with Benign Lung Disease. $J$ Thorac Dis 2018; 10: 3532-3538. [CrossRef] [PubMed] 